\title{
Derivation Type
}

National Cancer Institute

\section{Source}

National Cancer Institute. Derivation Type. NCI Thesaurus. Code C41090.

The type of Derived Data Element that is being created. For example a Data Element that is derived/created by subtracting two dates represented by other data elements would be a Calculated Representation Type. Types include: Calculated, Complex Recode, Compound, Concatenation, Object Class, and Simple Recode. 